\title{
Erratum to: Genetic basis of destruxin production in the entomopathogen Metarhizium robertsii
}

\author{
Bruno Giuliano Garisto Donzelli • Stuart B. Krasnoff • \\ Yong-Sun Moon • Alice C. L. Churchill • \\ Donna M. Gibson
}

Published online: 20 March 2012

(C) Springer-Verlag 2012

\section{Erratum to: Curr Genet}

DOI 10.1007/s00294-012-0368-4

The name of the third author was mistakenly reported as Yong Sun-Moon. The correct spelling is Yong-Sun Moon.

The online version of the original article can be found under doi:10.1007/s00294-012-0368-4.

B. Giuliano Garisto Donzelli ( $₫) \cdot$ S. B. Krasnoff .

D. M. Gibson

Biological Integrated Pest Management Research Unit,

Robert W. Holley Center for Agriculture and Health,

USDA-ARS, 538 Tower Road, Ithaca, NY 14853, USA

e-mail: bdd1@ @ornell.edu

\section{Y.-S. Moon}

Boyce Thompson Institute for Plant Research,

Tower Road, Ithaca, NY 14853, USA

Present Address:

Y.-S. Moon

Department of Horticulture and Life Science,

Yeungnam University, 214-1 Dae-dong,

Gyeongsan-si, Gyeongsan 712-749, Republic of Korea

\section{A. C. L. Churchill}

Department of Plant Pathology and Plant-Microbe Biology,

Cornell University, Ithaca, NY 14853, USA 